\title{
SCHWARZ, Roberto. Seja como for: entrevistas, retratos e documentos. São Paulo: Duas Cidades; Editora 34, 2019.
}

\section{Bárbara DelRio Araújo}

Centro Federal de Educação Tecnológica de Minas Gerais (CEFET-MG), Belo Horizonte, Minas Gerais/Brasil

barbaradelrio.mg@gmail.com

http://orcid.org/0000-0001-5415-6981

Papa-fina é uma expressão popular utilizada para designar algo de boa qualidade, de muito sabor e preparado com excelência. É exatamente nesses moldes que se estrutura a mais recente obra do crítico literário Roberto Schwarz, Seja como for: entrevistas, retratos e documentos. Dividida em duas partes, uma delas é dedicada às entrevistas e outra a ensaios curtos que dissertam sobre literatura e ciências sociais. Além disso, a obra comporta prefácios e documentos, como o intitulado "Bastidores", no qual se revela a transcrição, sem alteração, de um parecer do DOPS sobre o texto "Cultura e Política no Brasil, de 1964-1969”, de Roberto Schwarz, publicado, inicialmente, na revista francesa Les Temps Modernes. Interessantíssimo é observar os comentários do redator que, além de expor o exaustivo trabalho de tradução, "consumindo $18 \mathrm{~h}$ de labor", classifica o texto de Roberto como "altamente intelectualizado", "aberto à exposição, que parece cínica (mas que não diz tudo) dos diversos planos desenvolvidos pela esquerda e seus subgrupos" (SCHWARZ, 2019, p. 13). Essa impressão não se restringe a esse arquivo e pode ser evidenciada ao longo de todos os escritos dessa obra, que apresenta, além do tom cotidiano, muita complexidade nas discussões, dando a entender que haja sempre algo a mais a se dizer. Deste modo, em função da concisão típica das resenhas, optei por destacar a síntese das entrevistas e os aspectos fundamentais dos ensaios.

\section{Entrevistas}

"Cuidado com as ideologias alienígenas" - Roberto Schwarz é questionado sobre o influxo estrangeiro no eixo da construção formativa 
nacional e, relembrando a discussão com Maria Sylvia de Carvalho Franco a respeito das ideias estarem fora (ou não) do lugar, o crítico reafirma sua posição de que as contradições apresentadas na adoção de modelos estão associadas à questão histórica de nossa condição de subdesenvolvimento. Assim, deixa claro que essa situação não é uma escolha entre ser a favor ou contra o influxo externo, mas um fato que nos obriga à convivência. A entrevista se encerra com uma reflexão de como são importantes a contradição e a parodização dos modelos externos para deflagramos a nossa diferença, que é objetiva e sempre comparativa.

"Encontros com a civilização brasileira" - Em um panorama sobre a trajetória de Roberto Schwarz, perguntas são lançadas para que ele reflita sobre as mudanças e continuidades nas noções metodológicas. Dessa forma, se reconhece que a obra $A$ sereia e o desconfiado é limitada e nela se desenvolveu apenas "a metade de seu programa", cuja maturação tem o seu auge no livro Ao vencedor, as batatas. Nessa revisão, o crítico reconhece que a tese adotada por Gyorgy Lukács, muito utilizada sobretudo nas análises de seu primeiro livro, não avança muito para as discussões em relação à arte moderna. Entretanto, ele constata a importância do húngaro e enuncia a necessidade de se ler Benjamin e Adorno: "penso que, sem forçar demais a mão, eles poderiam ser integrados" (SCHWARZ, 2019, p. 32).

"Que horas são?" - Nessa entrevista, Roberto Schwarz responde às perguntas a partir da necessidade de se valorizar as horas históricas e diz que isso é imprescindível ao labor do crítico literário. Schwarz indica ainda relações entre o Brasil e a América Latina, mas afirma que, embora compartilhem momentos semelhantes, ambos não têm o mesmo relógio. De toda forma, ele explica ser possível ver "através do outro" e revela como os países periféricos com sua modernização retardatária podem contribuir para entender a atualidade e as dimensões do capital.

"Um retratista de nossa classe social" - "A lição de Machado de Assis foi o grande apetite por cultura contemporânea, nunca deslumbrado e sempre a serviço do aprofundamento da experiência histórica que era sua". (SCHWARZ, 2019, p. 61)

"Machado de Assis: um debate" - Constrói-se aqui um debate acalorado sobre a obra de Machado de Assis e as análises desenvolvidas por Roberto Schwarz, sobretudo acerca da representação histórica. Críticos renomados como Luiz Felipe Alencastro, Francisco de Oliveira, José 
Arthur Giannotti, Davi Arrigucci Jr., Rodrigo Naves e José Antonio Pasta Jr. sabatinam Roberto que responde a todas as questões. A discussão tem seu ponto alto, quando Giannotti diz que a ênfase histórica desenvolvida nas análises acerca da obra machadiana deixa de lado questões importantes como o lado fantástico e a melancolia. Haveria ali reducionismo? A resposta logo vem: "O que faz - na minha opinião - o Machado não ser um paspalhão é exatamente isso. É que quando ele diz essas coisas, quando ele diz essas generalidades, ele diz sempre de maneira envenenada" (SCHWARZ, 2019, p. 75).

"Do lado da viravolta" - Essa entrevista relaciona os ensaios de Roberto Schwarz com o cenário político contemporâneo. Desse modo, Roberto comenta que o ex-presidente Fernando Collor de Mello, pela desfaçatez de fachada, poderia ser um personagem machadiano. Discute também a tese do ex-presidente Fernando Henrique Cardoso e os estudos do historiador Fernando Novais a fim de mostrar como as ideias modernas no Brasil são sempre postiças e parecem fora do lugar, revelando falsa universalidade. Nesse âmbito, discutem-se as etapas do capitalismo e como a modernização parcial rechaça a mão de obra não especializada, fazendo com que os pobres desejem participar de um processo de exploração do qual são alijados. Destacam-se os estudos de Roberto Kurtz e a importância de se estudar a dependência nacional em conjunto com o desenvolvimento da América Latina e da Europa. Roberto Schwarz encerra defendendo o marxismo como método: "o marxismo no Brasil não foi abatido intelectualmente: foi largado com muito prejuízo" (SCHWARZ, 2019, p. 111).

"Braço de Ferro sobre Lukács" - Eva Corredor interpela Schwarz sobre os limites do pensamento lukacsiano no Brasil. Roberto chama a atenção sobre as especificidades nacionais e elucida: "eu não estou dizendo que Lukács não inspira. O que eu digo é que não se pode tomar o esquema dele e aplicá-lo à realidade brasileira do mesmo jeito que se pode fazer na Europa" (SCHWARZ, 2019, p. 129). Explica, por exemplo, que o conceito "proletário" trabalhado pelo húngaro não tem como ser equiparado no Brasil, país cuja industrialização não ocorreu de forma orgânica e completa. Esclarece, ainda, que o Estado Moderno se deu em ordem diferente e finaliza: "Devo muito a Lukács. Devo a ele meu esquema do romance europeu. Como ficou dito sua construção não corresponde às realidades brasileiras. Porém, como é uma notável formulação das grandes linhas da 
história social e literária europeia, ela faz ver os pontos em que a sociedade e a cultura brasileira se desvia de seus muitos estimados modelos europeus" (SCHWARZ, 2019, p. 149).

"Dimensão estética da realidade, dimensão real da forma artística" - A entrevista focaliza sobretudo as obras Dom Casmurro, de Machado de Assis, e Minha Vida de Menina, de Helena Morley. No primeiro, destaca-se a força histórica na fatura do romance; no segundo, é o inverso, preza pela força artística. Roberto Schwarz defende a complementariedade dos seus estudos sobre os textos machadianos, mostrando como ambos são frutíferos no que tange a matéria brasileira.

"Meninas Assombrosas" - Continuando as observações acerca de Dom casmurro e Minha Vida de Menina, Schwarz destaca a diferença estética entre as obras e, ainda que considere a obra machadiana mais sofisticada, enleva o livro de Helena Morley, dizendo que as inadequações são reveladoras.

"Maio de 1968"-Aqui o crítico relembra como viveu a efervescência política no Brasil, em 1968, durante os anos de chumbo. O estudioso destacou a importância da influência francesa nas passeatas da juventude e no pensamento esquerdista, mas deixou claro que esse influxo não substituía as questões internas ainda que fosse inegável a relação entre elas.

"Sequências Brasileiras" - Roberto Schwarz explica que o título do ensaio tem relação com a obra de Bertolt Brecht, mas sua análise não perde o foco nacional. Assim, reflete de modo descontraído sobre a designação que lhe impuseram de crítico sociológico: "esse rótulo colou e vai me acompanhar até a cova. Ele não é fácil de entender, embora a intenção depreciativa seja óbvia" (SCHWARZ, 2019, p. 186).

"Tira-dúvidas" - Schwarz reforça a afirmação de Antonio Candido de que estudar literatura brasileira é também fazer literatura comparada uma vez que a crítica literária executa a comparação, ainda mais por se tratar de um país periférico, cujas decisões estão sempre em relação aos modelos europeus. Nesse âmbito, o estudioso segue discutindo a formação da obra $O$ cortiço, de Aluísio Azevedo, em meio as teorias deterministas, além de analisar a poesia de Oswald de Andrade diante da efervescência das vanguardas. Toca ainda na obra Verdade tropical, de Caetano Veloso, frente às tendências entre outros grandes nomes. 
"Ao vencedor, as batatas 30 anos: crítica da cultura e processo social" - O estudioso comenta como, quando comparada a outros autores, a ironia machadiana é específica, apesar de formada no diálogo com outros modelos. Aqui, produz asserções sobre a forma objetiva e afirma que para entender melhor Machado de Assis é preciso olhar sempre os predecessores.

"Sobre Machado de Assis" - Miguel Conde pergunta sobre a figura de Machado de Assis e Schwarz esclarece que o artista entrou para o panteão como figura encasacada e conservadora. Contudo, artisticamente o que se vê é um ardor crítico inconformista e explorador dos impasses brasileiros. Reconhece que, nas obras, existem arcaísmos da escrita, mas esclarece que o tom é revelador e consistente; diferentemente de uma linguagem barbosiana, o arcaísmo tem função estética. Schwarz comenta ainda a posição crítica de autores como Helen Caldwell, John Gledson e Abel Barros Baptista.

"Degradação e desigualdade" - Marcos Strecker questiona sobre a apresentação de Schwarz na FLIP e indaga sobre a entrevista concedida ao jornal Folha de São Paulo, em 2007. Schwarz esclarece que, no primeiro, se dedica a Dom Casmurro em que o tema do adultério serve de isca para discutir a sociedade nacional; no segundo, a preocupação é com a reabertura democrática e como o capital derrota o trabalho. Nesse espírito, comenta também sobre obras literárias como Cidade de Deus e Tropa de elite.

"Sobre Antonio Candido" - Maria Augusta Fonseca pede que Roberto Schwarz discorra sobre os principais conceitos presentes na obra de Antonio Candido. Schwarz explica que os conceitos e métodos aparecem integradas nas análises do mestre. Ressalta que existe um equilíbrio entre a matéria brasileira e a configuração estética formal. "Redução estrutural" é citado como um exemplo de um conceito que não é rígido e aparece em dois ensaios magníficos: "Dialética da Malandragem" e "De cortiço a cortiço". O destaque se dá pela inovação e grande envergadura, pois neles parte-se de obras limitadas do ponto de vista estético, a saber Memórias de um sargento de milícias, de Manuel Antônio de Almeida, e O Cortiço, mas que são transfiguradas em configurações notáveis graças ao achado analítico de Antonio Candido.

"Retrato de Grupo" - Nessa entrevista, Roberto Schwarz comenta sobre a sua formação e conta que veio para o Brasil com a família para fugir das perseguições nazistas. Logo após o falecimento de seu pai, a figura de Anatol Rosenfeld assumiu o papel de tutor de leituras, inclusive 
incentivando-o a ir à USP para escolher uma graduação. Na Universidade, Roberto descreve a aproximação com Antonio Candido e com outros professores exemplares, através dos seminários sobre $O$ Capital, de Karl Marx. Destaca temas como marxismo, progressismo, anti-imperialismo, terceiro mundismo como foco da discussão.

"Um narrador camaleônico" - A entrevista começa com a interpelação do entendimento de Caetano Veloso, expressos na Folha de São Paulo, sobre a análise de Roberto Schwarz acerca da obra Verdade tropical. Roberto explica que Caetano Veloso não foi claro na reportagem e revela que, ao fazer a interpretação da obra, não tinha a intenção de nomeá-lo de autor direitista, mas de mostrar que se enunciava no romance autobiográfico um "herói representativo e problemático". Apresentando os matizes que compõe a força estética do livro, Roberto evidencia a contradição entre as atitudes do autor Caetano Veloso e as assertivas da obra que expõe, por exemplo, complacência com a ditadura e com a guerrilha ao mesmo tempo: "Verdade tropical deve muito de seu interesse literário a certa desfaçatez camaleônica em que Caetano, que é seu narrador, é mestre" (SCHWARZ, 2019, p. 301).

"A lata de lixo da história" - A discussão se inicia pelo âmbito teatral de 1960, comentários acerca do teatro de Zé Celso, do cinema de Glauber Rocha, além das artes visuais marcam a caracterização subversiva. Roberto Schwarz comenta que $A$ lata de lixo da história foi escrita nesse ambiente convulsivo brasileiro, mas que foi terminada na Europa em função do AI-5. Diversos detalhes e caracterizações da peça são lançados, inclusive, uma relação íntima entre o enredo e o conto $O$ alienista, de Machado de Assis.

"Declaração de voto" - Comentários atualíssimos sobre a política nacional: "Para concluir, pensando em amigos da vida inteira, eu diria que, neste momento, a neutralidade entre Haddad e Bolsonaro é um erro histórico de grandes proporções" (SCHWARZ, 2019, p. 313).

"Cultura e Política, ontem e hoje" - A proposta inicial é discutir o Brasil e seu diálogo com a América Latina. Pensar, por exemplo, se Machado de Assis como alegoria brasileira não poderia ser um emblema das elites vizinhas que compartilharam a situação de colônia. A conversa se expande na comparação do tropicalismo a do movimento antropofágico como típicos do terceiro mundo. Assim, Roberto exibe um raciocínio matizado e retoma uma afamada frase que auxilia pensar a cultura no Brasil e na América 
Latina: "é mais fácil tornar o subdesenvolvimento em arte que superá-lo" (SCHWARZ, 2019, p. 320).

"Cultura e política agora" - Claudio Leal questiona Roberto Schwarz sobre o paradoxo das eleições democráticas atuais ao apresentar candidatos com discurso em favor da ditadura militar. O crítico dá uma aula sobre o tempo sombrio e a meia sombra de agora, concluindo que "os faróis da modernidade mundial muito perderam de sua luz" (SCHWARZ, 2019, p. 328).

Todo esse conjunto de entrevistas remontam um panorama que cobrem 50 anos - entre o AI-5 e as eleições de 2018 para presidência da República - propondo aproximações e distanciamentos, oferecendo uma reflexão acerca da inserção nacional no mundo do capital, sob a posição de país periférico, além de nos oferecer uma revisão dos ensaios do autor e as impressões de quando foram lançados. A segunda parte de Seja como for é composta por 15 ensaios inéditos, prefácios comentados, além de um relato sobre os anos de doutoramento de Roberto Schwarz. Sobre esse último, deixo a assertiva: "Grécia achou que era uma nota 10, pois a uma bosta não falta jamais o reconhecimento dos doutos. Além do que, a tese do Walter Benjamin também havia sido recusada a seu tempo" (SCHWARZ, 2019, p. 427).

\section{Ensaios}

Acredito que os textos da segunda parte possam ser agrupados no seguinte panorama:

a) reflexões acerca da importância e da amizade com autores, em que se destaca os nomes de Anatol Rosenfeld, Maurício Segall, José Guilherme Merquior, Antonio Candido, Paul Singer e Albert Hirschman;

b) análises sobre textos literários e incursões sociológicas, em que se interpreta a crônica de Luiz da Gama, a obra Modernidade Periférica, de Beatriz Sarlo, as artes plásticas de Sérgio Ferrero, além das cartas de Gilda de Melo e Souza;

c) por fim, há ainda escritos que se colocam como prefácios, documentos e breves anotações, todas potencialmente críticas como as palavras do autor no primeiro número da Revista Teoria e Prática em 1967: "Nossa revista não tem, portanto, um programa; tem convicções" (SCHWARZ, 2019, p. 336). 
Nesse aspecto, pode-se dizer que a contribuição dessa obra para compreender o pensamento de Schwarz está na sua perspectivação em acompanhar a dinâmica e a versatilidade da interpretação do crítico, demonstrando o quanto as suas convicções materialistas e históricas podem ser reelaboradas, sem perder o caráter crítico-dialético (e humano) fundamental na trajetória do autor.

Recebido em: 3 de janeiro de 2021.

Aprovado em: 28 de julho de 2021. 